\title{
Characterizing particle dispersion by image analysis in ICFB
}

\author{
Xiaolin Wei ${ }^{\mathrm{a}, *}$, Hongzhi Sheng ${ }^{\mathrm{a}}$, Wendong Tian ${ }^{\mathrm{b}}$ \\ a Institute of Mechanics, Chinese Academy of Sciences, Bei Si Huan Xi Lu. 15, Beijing 100080, PR China \\ ${ }^{\mathrm{b}}$ Institute of Engineering Thermophysics, Chinese Academy of Sciences, Bei Si Huan Xi Lu. 12 B, Beijing 100080, PR China
}

Received 16 August 2005; received in revised form 16 December 2005

Available online 24 May 2006

\begin{abstract}
A new particle image technique was developed to analyze the dispersion of tracer particles in an internally circulating fluidized bed (ICFB). The movement course and the concentration distribution of tracer particles in the bed were imaged and the degree of inhomogeneity of tracer particles was analyzed. The lateral and axial dispersion coefficients of particles were calculated for various zones in ICFB. Results indicate that the lateral diffusion coefficient in the fluidized bed with uneven air distribution is significantly higher than that in uniform bubbling beds with even air distribution. The dispersion coefficients are different along bed length and height.
\end{abstract}

(C) 2006 Elsevier Ltd. All rights reserved.

Keywords: Particle dispersion; Image analysis; ICFB

\section{Introduction}

Generally, the material uniformity due to axial mixing is better than lateral mixing in shallow fluidized bed. Lateral mixing of particles is of great importance to the operation of fluidized bed reactor. If the materials are not fully mixed laterally, the conversion efficiency of bed for reaction will reduce, even the accident of operating system might occur.

In fluidized beds, due to wall effect, fluidized air velocity decreases near the wall. This may result in a local internal circulating flow, induced by the velocity gradient of gasparticle flow. Similarly, the artificially uneven distribution of fluidized air can also result in a large-scale internal circulating flow, which makes bed materials distributed more evenly, and significantly improves lateral dispersion.

Due to more favorable properties of combustion and heat transfer, internally circulating fluidized bed (ICFB) has been utilized in fields of low-grade coal combustion and municipal and/or industrial solid waste incineration [1-3]. In ICFB, fuel may be quickly dried, collided,

\footnotetext{
* Corresponding author. Tel.: +86 10 62545533x3052; fax: +86 10 62561284.

E-mail address: xlwei@imech.ac.cn (X. Wei).
}

crashed, ignited, and burned through fully mixing of solid particles. Changing fluidized velocity in fuel heating zone is likely to control the volatile release rate, the combustion rate, and the heat transfer rate between high-temperature bed materials and fuel particles $[3,4]$. When the composition and size of fuels are abruptly changed, this may prevent emitting higher $\mathrm{CO}$ and $\mathrm{HC}$ in flue gas.

Lateral mixing of particles in bubbling beds or circulating fluidized beds has been widely investigated in detail [58]. Shi and Fan developed a fairly general correlation for estimating the lateral dispersion coefficients of particles as a function of the properties of fluidized particles and fluidizing air, and operating conditions [5]. Berruti et al. took into account radial and axial variations of the lateral dispersion coefficient and a modified empirical correlation is given [6]. Hyrea and Glicksmanb developed a method for approximating the axial and lateral distribution of solids in the upper region of a circulating fluidized bed (CFB) [7]. Bi et al. studied lateral mixing of coarse particles in fluidized beds with fine particles [8]. Recently, the image technique has also been used to get a comprehensive two-dimensional visualization in fluidized beds $[9,10]$. But there are not reports to calculate particle dispersion coefficients via the image analysis. 
In the present work, the tracer particle movement was measured through the image technique in ICFB. The lateral and axial diffusion coefficients of particles were calculated in the bed by the image data.

\section{Experimental system}

Fig. 1 shows the experimental system, including a fluidized bed, and video recording and processing system. The model is $600 \mathrm{~mm}$ long, $80 \mathrm{~mm}$ wide and $1200 \mathrm{~mm}$ high, which is approximately a 2-D test bed. The length ( $x$-direction) proportion of two fluidized beds and one moving bed is 1:2:1 (fluid bed: moving bed: fluid bed). An orifice distributor plate with $5 \mathrm{~mm}$ diameter holes is used, and the orifice area is $5 \%$ of total distributor area. The bed materials (with white color) and tracer particles are made by polypropylene, and tracer particle is dyed as black. The diameter of particles is about $3.0 \mathrm{~mm}$. The static bed height is $300 \mathrm{~mm}$. The high air velocity is employed in both sides of the bed $\left(5.4 U_{\mathrm{mf}}, U_{\mathrm{mf}}\right.$ is the superficial air velocity at minimum fluidization and $U_{\mathrm{mf}}=0.9 \mathrm{~m} / \mathrm{s}$ ), where the fluid-

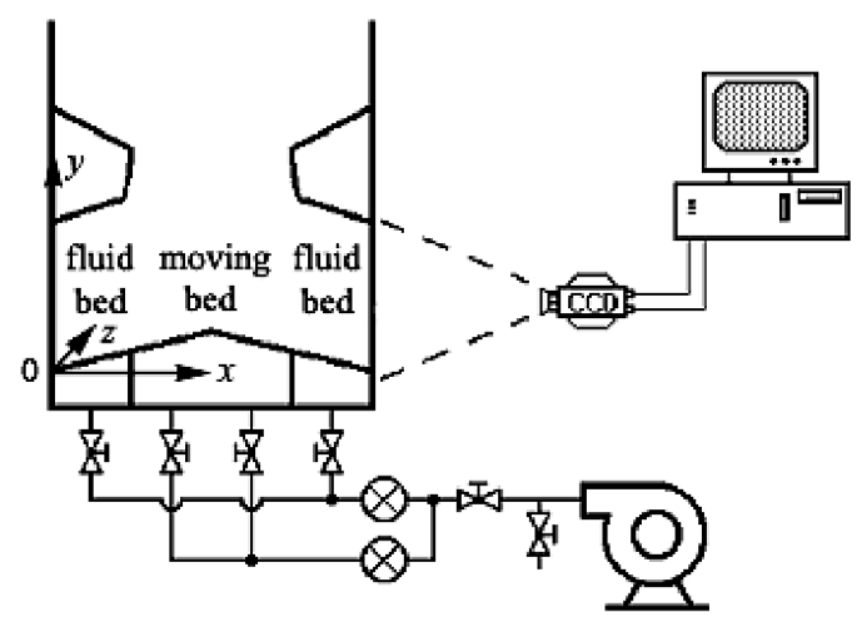

Fig. 1. Test system of the fluidized bed with uneven air distribution. Notations: $x$-length; $y$-height; $z$-width. ized bed is formed, defined as fluid bed or fluid zone. The low air velocity is used in the central bed $\left(1.8 U_{\mathrm{mf}}\right)$, where a moving zone is formed, defined as moving bed. Finally, two internal circulating flows are induced in the bed. The images of particle movement were recorded by a CCD camera through the glass window installed in the apparatus. The data were collected by a computer and processed by a special code. The air volume flow rate was measured by rotameters with $10 \%$ maximum error.

\section{Results}

\subsection{Experiment}

In the beginning of the test, tracer particles were quickly added into the moving bed zone (with lower air velocity). The mixing process of bed materials and tracer particle was recorded by the camera (see Fig. 2, only half of the bed length is shown and the centerline of the bed is right sideline of the figure). White color stands for bed materials and black for tracer particles. Higher air velocity is employed in left part of the bed and the fluidized zone is formed. Lower air velocity is used in right part and the moving zone is formed. Then an internal circulating particle flow is formed in the bed through uneven fluidized air distribution.

When tracer particles enter into the moving bed rightward, they quickly descend and disperse to the fluid zone leftward (see Fig. 2(a)). The tracer particles are moved laterally to the fluid zone as shown by white arrowhead in Fig. 2(b). Bed materials in the top of the bed move laterally to the moving zone as shown by black arrowhead in Fig. 2(b).

As the test continues, the laterally moving bed materials are pushed down by the particles in the moving zone as shown in Fig. 2(c). Then the tracer particle flow layer is broken down and separated by the revolving downflow. Tracer particles move to the fluid zone, where they are carried by the bubbles' wake and move upwards, whilst the forepart of tracer particle layer begins to mix with bed

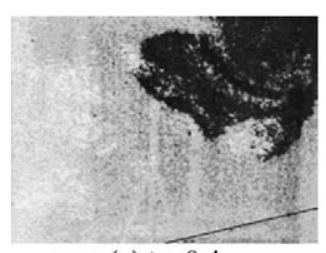

(a) $\mathrm{t}=0.4 \mathrm{~s}$

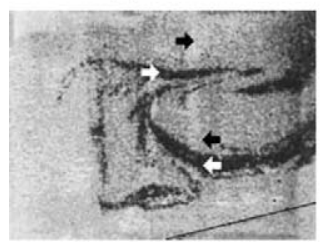

(e) $\mathrm{t}=2.0 \mathrm{~s}$

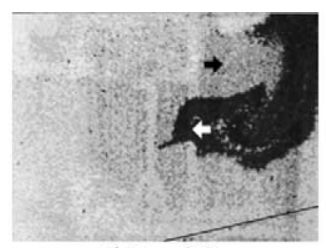

(b) $\mathrm{t}=0.8 \mathrm{~s}$

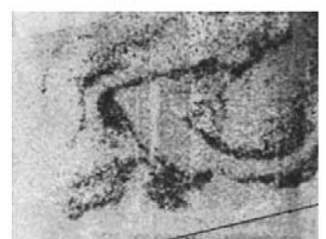

(f) $\mathrm{t}=2.4 \mathrm{~s}$

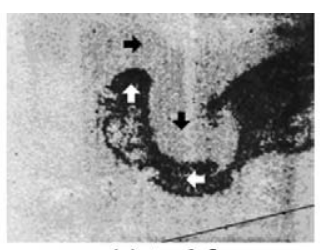

(c) $\mathrm{t}=1.2 \mathrm{~s}$

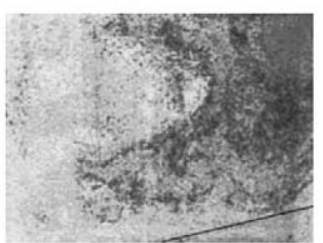

(g) $\mathrm{t}=3.2 \mathrm{~s}$

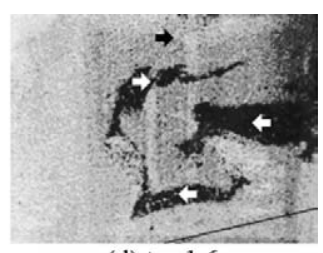

(d) $\mathrm{t}=1.6 \mathrm{~s}$

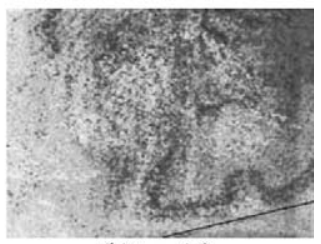

(h) $\mathrm{t}=4.0 \mathrm{~s}$

Fig. 2. Tracer particle dispersion in the fluidized bed with uneven air distribution. 
materials. As shown in Fig. 2(d), tracer particle flow layer is broken down by bed materials and continues to move laterally to the fluid zone in the bed bottom, whilst bed materials move from the fluid zone to the moving zone in the bed top and are mixed with tracer particles.

When the forepart of tracer particle layer returns to the moving zone from the fluid zone, there is no large area of tracer particles existing in the whole bed (see Fig. 2(e)). The tracer particles have been mixed with bed materials and the particle layer is separated into a few thinner layers. The gap between layers becomes more and more vague. Along with the revolving flow, the layers of tracer particles continues to roll up and the number of layers becomes more and more, as well as the layers becomes thinner and thinner (see Fig. 2(f)). Then the layers of trace particles gradually disappear as shown in Fig. 2(g). Finally, the trace particles totally disperse in the bed materials (see Fig. 2(h)).

\subsection{Image analysis}

In order to analyze the distribution of tracer particle concentration, the image is processed as following: the image is separated into $24 \times 18$ grids, each including $32 \times 32$ points of image elements. The color of each image element is determined by three primary colors, i.e., red, blue, and green, which corresponds to the color value from 0 to 255 in computer system. An average color value is calculated for each image element. A cut-off color value of the image element is used to determine if this image element stands for the tracer particle.

The numbers of tracer particles and total particles are counted by an image processing code. The ratio between two numbers is calculated as the tracer particle concentration in the grid. Because some black or white particles may just stay in the grid line, this will cause about $5 \%$ error of concentration of tracer particles. Fig. 3 shows the distribution of tracer particle concentrations with time. $x$ and $y$ stand for dimensionless length and height. The contour is used to describe the distribution of tracer particle concentrations and the gap between two lines stands for a concentration difference of 0.2 .

From Fig. 3, it can be seen that a swirl is induced by the internal-circulating flow of bed materials, which makes the tracer particles turn up and becomes better mixed with bed materials. During the initial mixing, there exist the higher concentration zones of the tracer particles, which then are separated into smaller zones and finally disappear.

\subsection{Inhomogeneity of tracer particles}

The degree of inhomogeneity may be used to describe the distribution of tracer particles in a fluidized bed. In the present work, the degree of inhomogeneity $h$ is simply evaluated using the measure

$h=\frac{\sigma}{n_{\text {ave }}}$

where $\sigma$ is the standard deviation of tracer particle numbers within grid squares; $n_{\text {ave }}$ is average value of tracer particle numbers in total fluidized bed.

$$
\begin{aligned}
& \sigma=\sqrt{\sum_{i=1}^{N_{\text {grid }}}\left(n_{i, \mathrm{par}}-n_{\text {ave }}\right)^{2} /\left(N_{\text {grid }}-1\right)} \\
& n_{\text {ave }}=\sum_{i=1}^{N_{\text {grid }}} n_{i, \text { par }} / N_{\text {grid }}
\end{aligned}
$$

where $n_{i, \text { par }}$ is the number of tracer particles within a grid square; $N_{\text {grid }}$ is the number of grid squares, which is determined by the image elements within one grid square, e.g., $N_{\text {grid }}=432$ for $32 \times 32$ image elements included in one grid square (total image elements in the fluidized bed is $760 \times 576)$.

The value of $h$ means a homogeneous distribution of tracer particles if it is close to zero. And the value $h$ increases with increasing degree of inhomogeneity in tracer particle

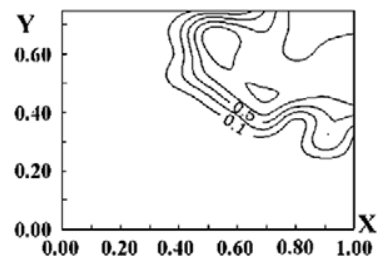

(a) $\mathrm{t}=0.4 \mathrm{~s}$

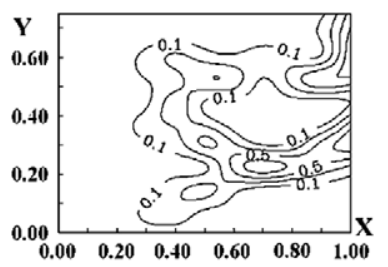

(e) $\mathrm{t}=2.0 \mathrm{~s}$

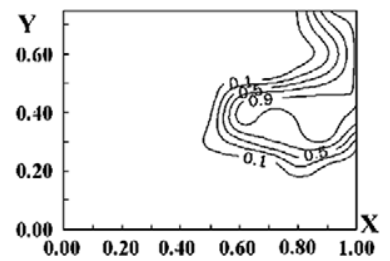

(b) $\mathrm{t}=0.8 \mathrm{~s}$

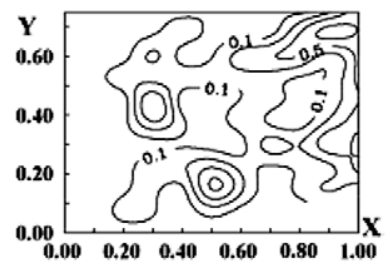

(f) $\mathrm{t}=2.4 \mathrm{~s}$

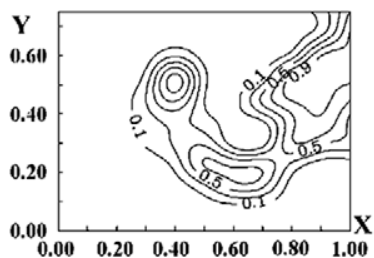

(c) $\mathrm{t}=1.2 \mathrm{~s}$

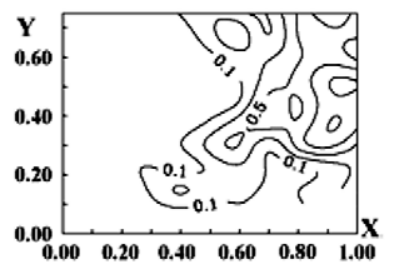

(g) $\mathrm{t}=3.2 \mathrm{~s}$

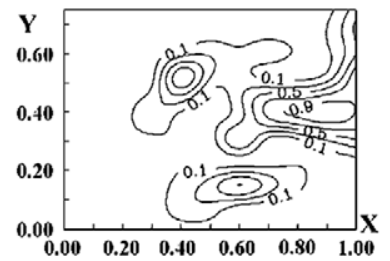

(d) $\mathrm{t}=1.6 \mathrm{~s}$

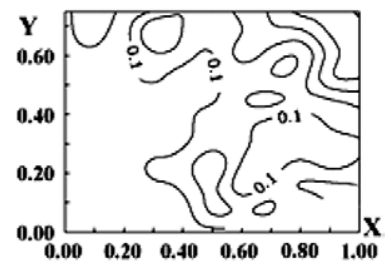

(h) $\mathrm{t}=4.0 \mathrm{~s}$

Fig. 3. The distribution of tracer particle concentrations with time. 
Table 1

The inhomogeneity $h$ for the tracer particle distribution on various scales

Time (s) Number of image elements in each grid, $N_{\text {ie }}$ and number of the grid squares, $N_{\text {grid }}$

\begin{tabular}{lllllll} 
& $4 \times 4$ & $8 \times 8$ & $16 \times 16$ & $32 \times 32$ & $64 \times 64$ & $128 \times 128$ \\
\hline 126,790 & 6745 & 1728 & 432 & 108 & 30 \\
\hline 4.0 & 2.79 & 2.67 & 2.55 & 2.30 & 1.99 & 1.81 \\
\hline
\end{tabular}

distribution. Table 1 gives $h$ value for various scales of divided grids. The value $h$ is dependent on the scale of grids and decreases with increasing image elements in each grid. So it is only a qualitative value to describe the degree of homogeneous distribution of tracer particles. Comparing with $h$ value for two graphs, the degree of inhomogeneity for the time $1.6 \mathrm{~s}$ is larger than that for $4.0 \mathrm{~s}$. Obviously, the distribution of trace particles becomes more homogeneous with time.

\subsection{Dispersion coefficients}

Because the test ICFB bed is approximately a 2-D model, the initially added tracer particles may be assumed evenly distributed along the bed width, i.e., $\partial / \partial z=0$. Therefore, the governing equation of particle dispersion in the fluidized bed is given as follows:

$\frac{\partial C}{\partial t}=\frac{\partial}{\partial x}\left(D_{\text {sr }} \frac{\partial C}{\partial x}\right)+\frac{\partial}{\partial y}\left(D_{\text {sa }} \frac{\partial C}{\partial y}\right)$

where $C$ - concentration of tracer particle, ratio of number of tracer particles to number of total particles, dimensionless; $D_{\mathrm{sr}}-$ lateral dispersion coefficient of tracer particles, $\mathrm{m}^{2} \mathrm{~s}^{-1} ; D_{\mathrm{sa}}-$ axial dispersion coefficient of tracer particles, $\mathrm{m}^{2} \mathrm{~s}^{-1} ; t$-time, $\mathrm{s} ; x$ - lateral distance along the dispersion direction, $\mathrm{m} ; y$ - axial distance along the dispersion direction, $\mathrm{m}$.

The concentration of tracer particles is obtained by image analysis for every grid (totally with $24 \times 18$ grids and each including $32 \times 32$ points of image elements). Then the bed zone is divided as four zones: upper and lower half of the fluidized bed as well as upper and lower half of the moving bed. For every zone, firstly the average concentration distribution of tracer particles along lateral or axial direction is calculated. Secondly, the concentration distribution of tracer particles for various time intervals is cited into Eq. (4). Finally the dispersion coefficients of ICFB in four zones are obtained. Table 2 shows the dispersion coefficients of tracer particles in the typical zones of ICFB.
In ICFB, gross circulation of particles can be induced by uneven distribution of fluidizing air. In the fluid bed zone, bed materials are carried up through higher velocity fluid. Then the erupting bubbles spread particles across the surface of the bed. Thus, particles at the surface will move towards the moving bed zone with lower velocity fluid, where the particles move downwards to the bed bottom and then move towards the fluid bed zone to fill the vacancy due to the rising particles. Therefore, an internally circulating particle flow is formed.

Near the surface and bottom in the ICFB, the particle motion occurs primarily along the lateral direction, thus the lateral dispersion coefficients are similar either in the fluid bed zone or the moving bed zone (see Table 2). But the coefficient in the lower half of the bed is bigger than the upper half. This is likely to be caused by the more regular bulk movement of the internally circulated bed material along the inclined air-distributor. In the axial direction, the particles move vertically and thus the axial dispersion coefficients are similar either in the lower half of the bed or the upper half. The axial dispersion coefficients in the fluid bed zone are bigger than that in the moving bed zone because of the higher air velocity employed in the fluid bed.

In uniform bubbling beds, particles flow upwards in the regions where bubbles rise and downwards elsewhere and thus particles disperse in the bed. Some equations of particle dispersion coefficients are induced by experimental methods for bubbling beds. The equations in Refs. [5,11] are selected to calculate the lateral and axial particle dispersion coefficients in uniform bubbling beds. The equations are given as follows:

$\frac{D_{\mathrm{sr}}}{\left(u-u_{\mathrm{mf}}\right) h_{\mathrm{mf}}}=0.46\left[\frac{\left(u-u_{\mathrm{mf}}\right) d_{\mathrm{p}} \rho_{\mathrm{f}}}{\mu_{\mathrm{f}}}\right]^{-0.21}\left[\frac{h_{\mathrm{mf}}}{d_{\mathrm{p}}}\right]^{0.24}\left[\frac{\rho_{\mathrm{s}}-\rho_{\mathrm{f}}}{\rho_{\mathrm{f}}}\right]^{-0.43}$

$D_{\mathrm{sa}}=1.058\left(\frac{d_{\mathrm{p}}^{3} \rho_{\mathrm{f}}\left(\rho_{\mathrm{s}}-\rho_{\mathrm{f}}\right) g}{\mu_{\mathrm{f}}^{2}}\right)^{-0.368}\left[g\left(u-u_{\mathrm{mf}}\right)\right]^{1 / 3} D_{\mathrm{t}}^{3 / 4}$

where $D_{\mathrm{sr}}$ - particle lateral dispersion coefficient, $\mathrm{m}^{2} \mathrm{~s}^{-1}$; $D_{\mathrm{sa}}-$ partical axial dispersion coefficient, $\mathrm{m}^{2} \mathrm{~s}^{-1} ; D_{\mathrm{t}}$ equivalent diameter of fluidized bed, $\mathrm{m} ; u$ - fluidized air velocity, $\mathrm{m} \mathrm{s}^{-1} ; h$ - height of fluidized bed, $\mathrm{m} ; d_{\mathrm{p}}$ - particle diameter, $\mathrm{m} ; \rho$ - density, $\mathrm{kg} \mathrm{m}^{-3} ; \mu$ - viscosity coefficient, $\mathrm{kg} \mathrm{m}^{-1} \mathrm{~s}^{-1}$. Subscript: $\mathrm{mf}-$ minimum fluidized condition; $\mathrm{f}$ - fluid; s - particle.

The coefficients are shown in Table 3 using the same fluidized air velocities as in ICFB. In uniform bubbling beds,

Table 2

The dispersion coefficients of tracer particles in the typical zones of ICFB

\begin{tabular}{lllll}
\hline $\begin{array}{l}\text { Dispersion coefficients } \\
\left(\times 10^{-4} \mathrm{~m}^{2} \mathrm{~s}^{-1}\right)\end{array}$ & $\begin{array}{l}\text { Upper half of the fluid bed } \\
U=5.4 U_{\mathrm{mf}}\end{array}$ & $\begin{array}{l}\text { Lower half of the fluid bed } \\
U=5.4 U_{\mathrm{mf}}\end{array}$ & $\begin{array}{l}\text { Upper half of the moving bed } \\
U=1.8 U_{\mathrm{mf}}\end{array}$ & $\begin{array}{l}\text { Lower half of the moving bed } \\
U=1.8 U_{\mathrm{mf}}\end{array}$ \\
\hline$D_{\mathrm{sr}}$ & 14.3 & 25.1 & 13.7 & 22.9 \\
$D_{\mathrm{sa}}$ & 31.8 & 30.8 & 11.3 & 13.7 \\
\hline
\end{tabular}


Table 3

The dispersion coefficients of tracer particles in uniform bubbling beds

\begin{tabular}{lccc}
\hline $\begin{array}{l}\text { Dispersion coefficients } \\
\left(\times 10^{-4} \mathrm{~m}^{2} \mathrm{~s}^{-1}\right)\end{array}$ & $U=5.4 U_{\mathrm{mf}}$ & $U=3.6 U_{\mathrm{mf}}$ & $U=1.8 U_{\mathrm{mf}}$ \\
\hline$D_{\mathrm{sr}}$ & 8.7 & 5.9 & 2.4 \\
$D_{\mathrm{sa}}$ & 28.5 & 23.9 & 16.2 \\
\hline
\end{tabular}

the axial dispersion coefficient is several times higher than the lateral coefficient and thus particle dispersion occurs primarily along the axial direction. Compared with the results in Tables 2 and 3, although the axial dispersion coefficients are similar, the lateral coefficient in ICFB is several times larger than that in uniform bubbling beds and it has approached the axial dispersion coefficient. This is caused by the particle internal circulating flow in ICFB.

\section{Conclusions}

The particle image technique was developed to analyze the movement course and the dispersion of tracer particles in ICFB. The concentration distribution and the degree of inhomogeneity of tracer particles were calculated and evaluated for various particle dispersion graphs. An internal circulating particle flow may form in the fluidized bed through uneven air distribution, which makes the tracer particles disperse and become more and more evenly mixed. The degree of inhomogeneity $h$ is used to evaluate the distribution of tracer particles. The value $h$ decreases with increasing dispersed time. In ICFB, the particle motion occurs primarily laterally and axially, thus the lateral and axial dispersion coefficients are similar. The axial dispersion coefficients in the fluid bed zone are larger than that in the moving bed zone because of the higher air velocity. The lateral coefficient in ICFB is several times larger than that in uniform bubbling beds and this is caused by the particle internal circulating flow in ICFB.

\section{Acknowledgements}

Financial Support by the Chinese Natural Science Foundation (Project No. 50376068 and No. 59776023) is acknowledged. The authors would like to thank Mandi Sun, Hongce Zhang, and Chunxia Zhang for their help on this work.

\section{References}

[1] H. Saito, S. Kosugi, K. Sato, The revolving-type fluidized-bed incinerator - its basic performance in MSW combustion, Waste Manage. Res. 6 (3) (1988) 261-270.

[2] A. Reichhold, H. Hofbauer, Internally circulating fluidized bed for continuous adsorption and desorption, Chem. Eng. Process. 34 (6) (1995) 521-527.

[3] H.Z. Sheng, X.L. Wei, J. Li, W.D. Tian, J. Jin, H.A. Jiang, J.B. Cao, J. Gao, Heat-transfer study of external superheater of CFB incinerator, Environ. Eng. Sci. 21 (1) (2004) 39-44.

[4] T. Oshita, T. Higo, S. Kosugi, N. Inumaru, Formation of internal circulation and control of overall heat-transfer coefficient in a fluidized-bed boiler, Heat Transfer-Jpn. Res. 23 (4) (1994) 349-363.

[5] Y.F. Shi, L.T. Fan, Lateral mixing of solids in batch gas-solids fluidized beds, Ind. Eng. Chem. Process Des. Dev. 23 (2) (1984) 337341 .

[6] F. Berruti, D.S. Scott, E. Rhodes, Measuring and modeling lateral solid mixing in a 3-dimensional batch gas solid fluidized-bed reactor, Can. J. Chem. Eng. 64 (1) (1986) 48-56.

[7] M.R. Hyrea, L.R. Glicksmanb, Axial and lateral solids distribution modeling in the upper region of circulating fluidized beds, Powder Technol. 110 (1/2) (2000) 98-109.

[8] J. Bi, G. Yang, T. Kojima, Lateral mixing of coarse particles in fluidized-beds of the fine particles, Chem. Eng. Res. Des. 73 (A2) (1995) 162-167.

[9] R.C. Chen, L.S. Fan, Particle image velocimetry for characterizing the flow structure in three-dimensional gas-liquid-solid fluidized beds, Chem. Eng. Sci. 47 (13/14) (1992) 3615-3622.

[10] Y. Bin, M.C. Zhang, B.L. Dou, Y.B. Song, J. Wu, Discrete particle simulation and visualized research of the gas-solid flow in an internally circulating fluidized bed, Ind. Eng. Chem. Res. 42 (1) (2003) 214-221.

[11] G.S. Lee, S.D. Kim, M.H.I. Baird, Axial mixing of fine particles in fluidized beds, Chem. Eng. J. 47 (1) (1991) 47-50. 